\title{
SHAKESPEARE E O DRAMA SATÍRICO
}

\author{
Erick Ramalho* \\ Centro de Estudos Shakespeareanos
}

\begin{abstract}
RESUMO
Ao proceder a uma breve recensão dos estudos que relacionaram o drama satírico grego às tragédias de Shakespeare, bem como a $O$ conto de inverno, busco demonstrar que esses achados mostram-se também corretos no que diz respeito à comédia, ao menos conforme sequenciada em Sonho de uma noite de verão. Para tanto, examino a paródia e o burlesco na peça como indicativos de um modo literário inserido nessa comédia shakespeariana, e por ela veiculado, com raízes que podem ser encontradas no drama satírico grego não menos do que na perspectiva algo mesclada dos teóricos do início da modernidade (anteriores a Casaubon) acerca do satírico tanto como o gênero grego quanto como a sátira em latim, a ele não relacionada.
\end{abstract}

\section{PALAVRAS - CHAVE}

Shakespeare, Drama satírico, Sonho de uma noite de verão

Pela tradição crítica desenvolvida no século XVII, alentada pela filologia do século XIX e expandida pelas interpretações teórico-literárias do século XX, pôde-se desenvolver um corpo de estudos sólido, amplo e, ao mesmo tempo, detalhado das formas da inuentio de Shakespeare, bem como de seus modos de reapropriação e recriação dos clássicos no palco elisabetano. ${ }^{1}$ Trata-se de estudos em sua maioria extremamente úteis pelas anotações sistemáticas e descrições analíticas que permitem identificar em detalhes as citações e alusões na Shakespeariana a autores da Antiguidade Clássica e, também, a obras medievais em vernáculo que permitiram a transposição para o início da modernidade inglesa de autores gregos e latinos - entre os quais Plutarco, Ovídio, Sêneca, Plauto e Terêncio têm maior significância.

Ao lado desta e respeitosa aos seus achados, conquanto almeje suprir-lhes as lacunas e inovar a tradição crítica, firma-se, desde o final século XX, outra forma de abordagem

\footnotetext{
*erickramalho@uol.com.br

${ }^{1}$ Para o texto em inglês de Shakespeare, utilizo a edição das obras completas por Wells \& Taylor (Oxford, 1986) e, para o texto em língua portuguesa, a minha tradução anotada. Indicam-se as citações pelos números de ato, cena e versos, respectivamente. Todas as demais fontes e estudos de outras línguas são cá citados em minha própria tradução. Ao longo deste artigo, cumpre informar ainda, valho-me apenas pontualmente de exemplos e tópicos tratados em duas de minhas palestras sobre este tema, a primeira realizada na FALE/UFMG em 2006 e a outra, na UFV, em 2007. Ambas, contudo, são destituídas do caráter de argumentação e das conclusões que ora se apresentam e que garantem o ineditismo deste artigo.
} 
da relação entre a obra de Shakespeare e os autores antigos que se faz mais arriscada por mostrar-se não raro extrínseca ao texto literário, valendo-se, por vezes em excesso, de informações contextuais mais do que de evidências textuais. Contudo, conduzidos com competência, os estudos sérios que se enquadram nesta abordagem fornecem evidências plausíveis e contribuições relevantes aos estudos shakespearianos, em particular à confluência, ora vislumbrada, entre a obra do Bardo e o teatro dos antigos gregos, como bem o demonstram as pesquisas de H. D. F. Kitto ${ }^{2}$ e de G. K. Hunter. ${ }^{3}$ Análises desta natureza também contribuem para o melhor entendimento da recepção moderna dos textos da Antiguidade Clássica, o que complementa o trabalho basilar de crítica textual, conforme se observa em estudos de R. Mitchell-Boyask, ${ }^{4}$ de M. Ewans, ${ }^{5}$ de M. S. Silk ${ }^{6}$ e, com menções a Macbeth, também naquele de F. MacIntosh. ${ }^{7}$

O problema que motiva esses estudos e, em parte, também o presente artigo, são o entendimento e a análise dos modos pelos quais Shakespeare parece recriar aspectos do teatro antigo a partir de modelos de poetas trágicos gregos cujas obras provavelmente não leu no original, pois para tal não há evidências. Todavia, isto não impede o conhecimento por parte de Shakespeare do drama ático, dadas as múltiplas formas de circulação desses textos, bem como do exercício de sua influência, entre os autores renascentistas. Alenta-se a importância dessa discussão, com efeito, no exame que L. Schleiner ${ }^{8}$ faz da disseminação de traduções latinas das tragédias áticas, na Inglaterra dos séculos XVI e XVII, para além das edições bilíngues similares àquela da Ilíada que traz, ao lado dos versos gregos, a transposição inglesa deles feita pelo poeta George Chapman e que veio a lume em 1616, ano da morte de Shakespeare. Schleiner bem cumpre o seu escopo primeiro de demonstrar como textos da tragédia ática podem ter sido lidos ou, ao menos, conhecidos por Shakespeare em latim - língua em que, como se sabe, o dramaturgo possuía maiores chances de sucesso do que em grego ${ }^{9}$ - como, por exemplo, por meio de um livro com tragédias gregas reunidas em tradução latina que foi encontrado na casa de Ben Jonson, ilustre dramaturgo amigo de Shakespeare.

\footnotetext{
${ }^{2}$ KITTO. Form and Meaning in Drama: A Study of Six Greek Plays and Hamlet, 1987.

${ }^{3}$ HUNTER. Dramatic Identities and Cultural Tradition: Studies in Shakespeare and his contemporanies.

${ }^{4}$ MITCHELL-BOYASK. On the Uses and Abuses of Girard and Shakespearean Criticism.

${ }^{5}$ EWANS. Patterns of Tragedy in Sophokles and Shakespeare.

${ }^{6}$ SILK. The Greek Tragedians and Shakespeare.

${ }^{7}$ MAcINTOSH. The Big Speech and the Lament in Ancient Greek and Modern Irish Tragic Drama. ${ }^{8}$ SCHLEINER. Latinized Greek Drama in Shakespeare's Writing of Hamlet.

${ }^{9}$ É conhecido e já bastante discutido o verso com que Ben Jonson, em poema que serve de homenagem póstuma ("On Shakespeare"), compara o Bardo aos maiores trágicos gregos e latinos, apesar de seu "small Latine and lesse Greeke", isto é, de deu seu pouco latim e ainda menos grego. Shakespeare frequentara a escola, grammar school, cujo currículo se funda no estudo de latim - e do também do grego, em algumas instituições - e nas tarefas de tradução e versão, assim em prosa, como em verso, de autores clássicos, pelo que teria conhecimentos suficientes para ler Sêneca com certa facilidade. Se invejável hoje em dia, tal conhecimento de latim não se comparava ao de Jonson nem ao de outros poetas proficientes e capazes de compor versos nas línguas clássicas, como John Milton, por exemplo. Cf. BALDWIN. William Shakespeare's Small Latine and Lesse Greeke; BARKAN. What did Shakespeare read?; e MIOLA. Shakespeare's reading. Sobre o ensino das línguas clássicas à época, cf. RAMALHO. Estudo Introdutório.
} 
Igualmente significante é o estudo de S. Dewar-Watson ${ }^{10}$ acerca da presença homérica como "modelo tragicômico" (tragicomic model) em duas peças da última fase shakespeariana, entre, aproximadamente, 1605 e 1611. Ciente de que se tem quase por certo que Shakespeare jamais leu a Odisseia, ao menos em grego, e de que a primeira tradução inglesa desse épico não fora publicada anteriormente a 1614 ou 1615, Dewar-Watson traça possíveis meios pelos quais Shakespeare teria conhecido e transposto partes desses versos homéricos. Aponta, nestes termos, a confluência entre a figuração do Ciclope na Odisseia e a caracterização de Calibã na Tempestade, ambos entremeados às relações entre natureza (nature) e cultivo/ cultura (nurture), e remete à caracterização da vida anti-social do Ciclope em rejeição às instituições cívicas, em particular entre os versos 106 e 115 do nono canto da Odisseia, ou seja, o episódio de Polifemo - o qual, recorde-se, serve de mote à paródia construída no Ciclope, drama satírico euripidiano. ${ }^{11}$

Para fazê-lo, além das fontes narrativas da época do helenismo (e.g., Plutarco a influenciar a caracterização dos monarcas shakespearianos; Luciano de Samósata a surgir em Timão de Atenas, peça cuja autoria Shakespeare dividiu com Thomas Middleton), Dewar-Watson assinala as discussões teóricas, vigentes no início da modernidade inglesa, acerca da Poética de Aristóteles, obra em que se menciona o drama satírico, conforme se tratará adiante.

Por ora, cumpre asseverar que é por via semelhante e com objeto de estudo análogo a estes que pretendo inserir o presente estudo no âmbito das análises acerca dos modos possíveis, e prováveis, de realização dramática e de modulação cênica da matéria literária pelos quais Shakespeare parece verter elementos do drama satírico grego particularmente na peça Sonho de uma noite de verão (A Midsummer Night's Dream, doravante Sonho...). Para tanto, em meio a fortuna crítica acerca deste tópico, recorde-se, de início, a asserção feita por Walter Kaufmann relativamente às peças de Shakespeare quando comparadas às obras de Ésquilo e de Sófocles: “(...) the satyr play is absorbed by the tragedy: instead of appearing as a separate member of a series of plays, it appears within the tragedy in the form of Shakespeare's famous comic scenes." [...o drama satírico é absorvido pela tragédia: em vez de aparecer como um membro separado de uma série de peças, ele aparece dentro da tragédia na forma das famosas cenas cômicas de Shakespeare].

\footnotetext{
${ }^{10}$ DEWAR-WATSON. Shakespeare's Dramatic Odysseys.

${ }^{11}$ Outra forma possível de influência é apontada por JONES (The Origins of Shakespeare, p. 85-118) ao assinalar que Shakespeare teria escrito Tito Andrônico e Júlio César à luz das versões feitas em neolatim por Erasmo de Roterdã das tragédias euripidianas Hécuba e Ifigênia em Aulis. Também Ovídio retratou o drama satírico em sua obra, uma das principais fontes das re-apropriações no palco elisabetano, lida por Shakespeare em tradução e possivelmente no original latino. Fundamentado em Sutton, AMBROSE (Family Loyalty and Bretrayal in Euripedes' Cyclops and Alcestis) demonstra como, no canto oitavo das Metamorfoses, deriva-se do drama satírico a paridade de exemplos de traição familiar entre o pai Erisícton e sua filha, assim como entre Cila e seu pai Niso. De maneira mais patente, aponta Ambrose, o poeta refere-se a um drama satírico, que parece ser Amantes de Aquiles (Achilleos erastai), nos Tristia (2.409-12): "est et in obscenos commixta tragoedia risus, / multaque praeteriti uerba pudoris habet; / nec nocet auctori, mollem qui fecit Achillem, / infregisse suis fortia facta modis." [e há tragédia misturada ao riso obsceno, a qual tem muitas palavras de arrojado pudor; e não traz prejuízo ao autor, que tornou Aquiles suave, ter-lhe enfraquecido os feitos de força com os seus modos].
} 
Como se vê, Kaufmann argumenta que é por meio dos elementos do drama satírico grego que Shakespeare concebe as cenas de alívio cômico (comic relief) emblemáticas de suas tragédias, entre as quais são proeminentes a cena do porteiro bêbado em Macbeth e os diálogos dos coveiros entre si e com Hamlet, na peça à qual este último dá nome. Como se observa, em A. Dihle ${ }^{12}$ e Northrop Frye é de fato recorrente na crítica essa associação presumida entre os momentos de riso na tragédia shakespeariana e a encenação do drama satírico na Grécia, apresentado que era em festivais intercalando-se-o às tragédias, para contrabalançar os estados de espírito, em função de intervalo cômico. ${ }^{13}$ Além das cenas cômicas de Macbeth e Hamlet consideradas por Kaufmann, Frye menciona a presença da personagem que carrega serpentes em Antônio e Cleópatra e, ainda, as cenas de farsa com clowns no Fausto, tragédia de Christopher Marlowe, contemporâneo de Shakespeare que antecipa a obra de Goethe. Trata-se, segundo o crítico canadense, de um "contraponto satírico" (satyric counterpoint) da natureza que subjaz ao drama elisabetano, o qual, por isso, "(...) so baffled Classically-minded critics who had forgotten about the satyr-play" [...tanto frustraram críticos de tendência clássica que haviam esquecido o drama satírico]. ${ }^{14}$

A menção ao Fausto é aí indicativa, ademais, dos meios pelos quais o drama satírico deu-se a conhecer em vernáculo na Inglaterra. Outro meio de difusão do gênero grego foi um próprio drama satírico composto e encenado em neolatim na Universidade de

\footnotetext{
${ }^{12}$ Segundo quem, "The untroubled jollity of these satyr plays reveals the true scope of Aeschylean drama, which may justly be likened to that of Shakespeare" [a ledice destituída de inquietações desses dramas satíricos revela o verdadeiro escopo do drama esquiliano, o qual pode justamente ser comparado àquele de Shakespeare]. DIHLE. A History of Greek Literature from Homer to the Hallenistic Period, p. 1.016.

${ }^{13}$ SLENDERS (Het Griekse satyrspel, p. 25) assinala: "Evenals de tragedie ontleent het satyrspel zijn stof aan de mythologie, maar in tegenstelling tot de tragedie is de behandeling vrolijk van aard. Demetrius

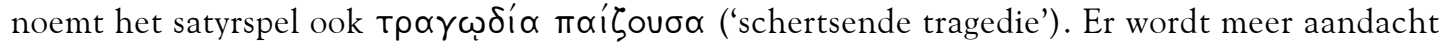
geschonken aan de aspecten van het dagelijks leven. Wat de toon betreft, lijkt het satyrspel enigszins op de (Oude Attische) komedie. Voor meer dan de helft van alle satyrspelen geldt zelfs, dat de stof ook in komedies wordt behandeld. Verder geldt voor beide genres dat een happy ending verplicht is." [Outrossim, da tragédia deriva o drama satírico sua matéria relativamente à mitologia, embora, em contraste com a tragédia, haja o tratamento ledo do modo [poético]. Demétrio denomina o drama

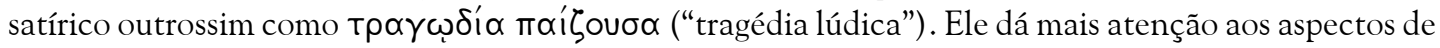
funcionamento cotidiano. No que diz respeito ao tom, o drama satírico assemelha-se em particular à comédia (ática antiga). Em mais da metade de todos os dramas satíricos pode-se dizer, com efeito, que a matéria é a mesma que se dá a tratar nas comédias. Ademais, aplica-se a ambos os gêneros que um happy ending se faça obrigatório]. A referência feita é à conhecida seção de número 169 da obra Do

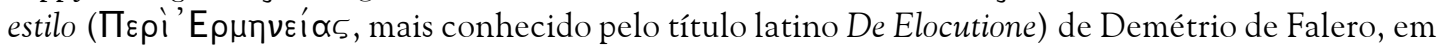

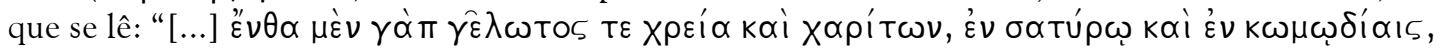

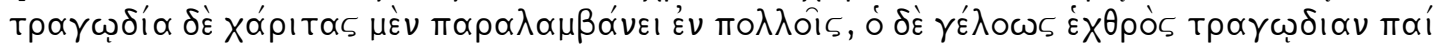

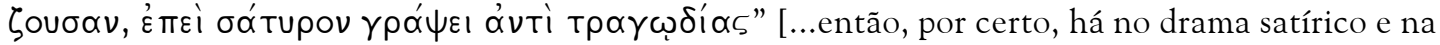
comédia a necessidade tanto de riso quanto de graça; a tragédia, porém, muitas vezes traz para si a graça, mas o riso é-lhe inimigo - quem escreve uma tragédia caçoante, escreve, portanto, um drama satírico em vez de uma tragédia].

${ }^{14}$ FRYE. Anatomy of Criticism, p. 292. Este ponto de vista é corroborado por SYDNEY; WILLIAMSON (Antony and Cleopatra, p. 136), segundo quem "[...] the satyr play as interlude makes its appearance not inappropriately in Antony and Cleopatra, in the "Egyptian Bacchanals' aboard Pompey's galley". [... o drama satírico como interlúdio faz sua aparição de maneira não inapropriada em Antônio e Cleópatra, nos "Bacanais Egípcios a bordo da gálea de Pompeu"].
} 
Oxford. Conforme S. Orgel, ${ }^{15}$ trata-se de um exemplar moderno de drama satírico, que infelizmente não chegou até nós, intitulado Alba e escrito pelo aluno oxoniano August Jones a trazer em sua apresentação atores quase nus, o que teria consternado, na plateia, a Rainha Elisabete e suas Damas de companhia. Fora produzido como parte das atividades dos alunos, tanto de Oxford como de Cambridge, que se punham a escrever, ao modo antigo, tragédias, comédias e drama satíricos para ser apresentados conjuntamente a peças clássicas em suas línguas originais, algo que ainda hoje se realiza nessas universidades.

Ainda outro importante meio de difusão foram as discussões teóricas, que reverberavam na prática poética e dramatúrgica, acerca da Poética de Aristóteles. Segundo assevera Dewar-Watson, fundamentados nessa obra, em que o Estagirita considera a

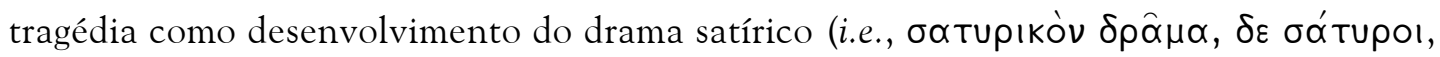
"sátiros" [1449a 20]), os teóricos modernos constituíram uma "ponte conceitual" (conceptual bridge) entre os gêneros antigos - entre os quais cita a tragédia, a comédia e o épico - e a tragicomédia renascentista (Renaissance Tragicomedy), então incipiente.

Resultam desse procedimento concepções modernas, por vezes bem peculiares, acerca do drama satírico, primeiro nos países continentais da Europa e, em seguida, junto aos teóricos ingleses contemporâneos de Shakespeare. Cumpre considerar a esse respeito a análise feita por R. Karlsson dos conceitos de "sátiro" conforme manifestados na Suécia do século XVIII, momento ulterior do início da modernidade, ainda a trazer os desdobramentos dela. Assinala o autor escandinavo que "Ordets etymologi har förvirrats av att man under renässansen härledde Satir från Satyr, d.v.s. från grekiska satyrspel. Detta har levt kvar i traditionen trots att Isaac Casaubon i De Satyrica 1605 avlivade den falska etymologin." [Tem-se confundido a etimologia do vocábulo desde a dedução renascentista de Satir a partir de Satyr, isto é, do drama satírico grego. Isto permaneceu na tradição a despeito de Isaac Casaubon em De Saytirica (1605) dirimir a falsa etimologia]. ${ }^{16}$ Casaubon é citado do mesmo modo por W. Slenders em estudo holandês em que defende: "Tot de Renaissance werd het satyrspel niet of nauwelijks bestudeerd. In de Renaissance kreeg de Cycloop van Eurípides en daarmee het satyrspel in zijn algemeenheid weer meer aandacht in het kader van discussies over het genre tragikomedie" [Até a Renascença o drama satírico não foi, ou quase não foi, estudado. $\mathrm{Na}$ Renascença, recebeu mais atenção das discussões sobre o gênero tragicomédia o Ciclope de Eurípides e, com isso, o drama satírico de forma geral, relativamente, portanto, à sua estrutura]. ${ }^{17}$

Os efeitos práticos na Shakespeariana dessas assimilações teóricas desvelam-se, por exemplo, na figura dos sátiros a dançar em $O$ conto de inverno, algo que J. Orgel atribui justamente a consequências no fazer teatral da noção da índole mordaz (biting) da sátira então mesclada ao drama satírico. Nestes termos, no seguinte excerto de

\footnotetext{
${ }^{15}$ ORGEL. The Authentic Shakespeare, p. 57.

${ }^{16}$ KARLSSON. Svensk-franska förhandlingar, p. 27 (nota 59). A diferenciação feita por Casaubon revela-se na própria divisão dos capítulos da obra, em que se analisa desde a afinidade (affinitas) do drama satírico (satyricae) com a tragédia e com a comédia áticas, os usos de satyri e satyrici pelos latinos até o exame dos escritos Donato e Horácio.
}

${ }^{17}$ SLENDERS. Het Griekse satyrspel, p. 23. 
Romanae Historiae Anthologia, obra didática escrita em inglês e publicada originalmente em 1614, o teólogo puritano Thomas Goodwin defende que as peças (plays) denominadas "Satyrae" adviriam

(...) from the lascivious and wanton Country Gods called Satyri, because the Actors in these Satyricall playes did vse many obscene Poems, and vnchast gestures, to delight their spectators. Afterward these kind of actors, as we may conjure, did assume such liberty vnto themselves, that they freely and without controlement, sharpely taxe \& censure the vices even of Kings, as well as of the Commons, insomuch that now we call every witti Poeme, wherein the liues and manners of men are sharpely taxed, A Satyre, or Satyricall Poeme.

[... dos deuses rurais, lascivos e licenciosos, chamados Sátiros, porque os atores nessas peças satíricas usavam realmente muitos poemas obscenos e gestos impudicos para deleitar seus espectadores. Posteriormente, esta espécie de atores, conforme podemos conjecturar, assumiu mesmo tal liberdade para si próprios, que reprovam e censuram, livremente e sem controle, de modo afiado, os vícios até mesmo dos reis, bem como dos cidadãos comuns, de modo que agora chamamos todo poema ardiloso, em que as vidas e as maneiras dos homens são reprovadas de maneira afiada, de sátira ou poema satírico. $]^{18}$

Esta indistinção vislumbra-se outrossim no tratado de poética The Arte of English Poetry, publicado em 1589, também em vernáculo, e atribuído geralmente a George Puttenham, embora às vezes arrogado a seu irmão, Richard. Nele se descreve uma espécie de poetas denominados satíricos ("Satyricques"), dentre os quais estariam Lucílio, Juvenal e Pérsio, a compor versos contra os vícios por meio de falas árduas e amaras ("rough and bitter speaches") sob a forma de inventivas chamadas sátiras ("inuectiues (...) called Satyres”) que serviriam para que atores caracterizados de sátiros ou silvanos ("gods of the woods (...) 'Satyres' or 'Silvanes”') as apresentassem em récita — forma de encenação, lembre-se, do drama elisabetano. ${ }^{19}$

Todavia, no que concerne ao presente objeto de estudo, não se deve partir da perspectiva simplista de que Shakespeare adapta para o palco uma indistinção teórica relativa à noção ou ao conceito de satírico. De outro modo, trata-se de perceber, no início da modernidade, desdobramentos de um processo de apropriações que se dava a conhecer desde a Antigüidade, pois, ainda no século IV a. C., segundo Sutton, ${ }^{20} \mathrm{O}$ drama satírico e a comédia não mais traziam diferenças de gênero que permitissem, em termos gerais, apontar-lhes como distintos. Posteriormente, a distinção se desfaz por completo na Roma antiga, onde não se contrastaria o drama satírico à tragédia e à

\footnotetext{
${ }^{18}$ GOODWIN. Romanae Historiae Anthologia Regognita et Aucta, p. 103.

${ }^{19}$ Os textos dramáticos elisabetanos eram declamados no palco e, a despeito das propriedades pictóricas, em nada desprezáveis, das apresentações, o verbo utilizado para descrever a condição da platéia era to hear, ouvir, ou seja, as peças eram para ser ouvidas, o que aumenta a importância da poesia (para fazer, por exemplo, com que um palco à luz do dia pareça tenebrosa noite como em Macbeth ou que um jovem ator seja Julieta), porquanto não destitua de importância os recursos cênicos, como, por exemplo, a utilização de bexigas de porco enchidas com corante vermelho que, postas sob a roupa de um ator, renderiam o sangue a jorrar quando a personagem era estocada por espada inimiga. A esse respeito, ver STYAN. Shakespeare's Stagecraft.
} ${ }^{20}$ SUTTON. The Greek Satyr Play, p. 82-3. 
comédia, segundo B. Seidensticker, mas com base na Fabula Atellana e, depois, nos mimos acrescentar-se-ia um epílogo à encenação trágica.

Logo, fundamentados sobretudo nos escritos horacianos, os teóricos e poetas renascentistas, como esperado, avançaram ainda mais na indistinção, pelo que se apropriam, ainda, dos versos satíricos em latim para que lhes servissem, ladeados pela paródia ao modo do drama satírico grego, aos propósitos do burlesco - que depois viria a se tornar um gênero dramático, durante Restauração, sob a pena de Gay e Sheridan, por exemplo. É neste ponto que o presente artigo busca trazer algo de novo a esta discussão, uma vez que faz incidir a análise não acerca de elementos do drama satírico assimilados por Shakespeare na tragédia com fins cômicos nem acerca da constituição de tragicomédia ou "romance", ${ }^{21}$ mas a veicular aspectos do drama satírico no gênero cômico elisabetano de que Sonho... é magnífico exemplar. ${ }^{22}$

Os elementos do drama satírico com os quais pode se fazer um paralelo na peça shakespeariana em questão dizem respeito, principalmente, ao modo com que se representa a conjunção entre dois dos três núcleos de personagens em que se divide a peça, a saber, a dos seres feéricos e dos trabalhadores braçais. São as relações mútuas das personagens desses grupos que engendram o riso derrisório da estrutura que é ensejada, mas desarmada pelo outro núcleo: o de Teseu, Hipólita e os jovens enamorados. Antes de proceder à análise dos elementos satíricos, convém pois recordar em resumo a trama da peça. Às vésperas de seu casamento com Hipólita, o Duque Teseu vê Egeu, que já conhecia, trazerlhe ao julgamento a filha Hérmia, desejosa de casar-se com um rapaz de nome Lisandro e, por isso, relutante em aceitar o moço, chamado Demétrio, que o pai queria-lhe por marido. O Duque dá como prazo a data próxima de seu casamento para que Hérmia decida-se entre acatar o desejo do pai e desposar Demétrio, por quem sua amiga Helena encontra-se apaixonada, ou enclausurar-se em um convento, alternativa proposta à morte com que se puniria, pela lei, a desobediência.

Desenvolve-se em paralelo a ação entre os seres feéricos, quando Oberon, Rei das Fadas, evoca seu arauto, o elfo Puck, para que, pingando o suco de uma flor mágica

\footnotetext{
${ }^{21}$ Forma taxonômica que a crítica encontrou para descrever aquelas peças do final da carreira de Shakespeare, como A tempestade, escritas para teatros fechados, com iluminação a vela de clima intimista, evocativo da magia por efeitos especiais (e.g. cordas a pender da parte superior coberta, no fundo do palco, que permitiam que atores "voassem"), as quais não se configuram claramente como tragédias, comédias ou peças históricas - divisão em si não destituída de problemas, consoante a classificação, já como tragédia, já como peça histórica, de Ricardo III, por exemplo.

${ }^{22} \mathrm{O}$ drama satírico sobrevive na modernidade pela assimilação de suas características em outros modos literários, de modo que, consoante Seidensticker, não há um renascimento do drama satírico na modernidade (Neuzeit) e as apresentações dos dramas clássicos, assim como a sua composição não constituíram uma escola (Schüle). Contudo, o próprio autor aponta a escrita de novos dramas satíricos também na contemporaneidade, como Trackers of Oxyrhyncos, de Tony Harrison (encenada pela primeira vez em 1988), o que o leva a concluir que o drama satírico, "Im Unterschied zu Tragödie und Komödie hat die Gattung weder einen nachhaltigen Einfluâ auf die europaischen Literaturen gehabt noch sich in immer neuen Metamorphosen erneuert und verjüngt" [Diferentemente da tragédia e da comédia o gênero nem exerceu influência duradoura na literatura européia nem se renovou ou se remoçou em metamorfoses sempre novas]. Como se percebe também no presente artigo, tal asserção não se comprova no que diz respeito à literatura inglesa do início da modernidade.
} 
nos olhos de Titânia, Rainha das Fadas, faça com que ela se apaixone pela primeira criatura que vir ao despertar de seu sono - a qual Oberon espera que seja uma besta, o que bem lhe serviria de desforra à esposa por conta da querela que então mantinha com ela acerca da posse, como pajem, de uma criança indiana. Ao divisar as vãs tentativas de Helena de ter o amor de Demétrio, Oberon ordena a Puck que goteje o sumo mágico nos olhos de Demétrio, rapaz ateniense que então se embrenhava no bosque em busca de Hérmia, que por ali fugia mais Lisandro rumo a uma localidade onde a lei não vigorava, o que permitiria seu casamento com ele.

Puck confunde Demétrio com Lisandro e, ao tentar corrigir o erro, acaba por fazer com que os dois se apaixonem por Helena, para estranhamento desta, assim como de Hérmia. Enquanto isso, um grupo de trabalhadores braçais que preparava a encenação de uma peça teatral para as celebrações das bodas de Teseu é assombrado por Puck, que enxerga em um deles, Novelo (Bottom), fantasiado de asno, uma besta propícia ao amor induzido em Titânia. Desfeitos os enganos que nutrem a comicidade da peça e restabelecida a paz matrimonial entre Oberon e Titânia, chega-se ao quinto ato da peça, em que os trabalhadores põem-se a encenar a cena que prepararam em cerimônia que, além de celebrar as núpcias de Teseu e Hipólita, servirá de bodas aos casais Hérmia e Lisandro, então de volta ao juízo, e Helena e Demétrio - este sob o efeito da flor que o fizera amá-la.

$O$ fato de a trama desenrolar-se em Atenas e em seus arrabaldes pode ser tomado como outro indício das relações entre a peça e a Antiguidade Clássica, em particular na concepção das fadas cuja natureza de traços medievais eiva-se de elementos gregos e latinos, como será visto mais à frente. Por outro lado, deve-se ter em mente que sói a Shakespeare tornar coetâneas de sua plateia quaisquer locais e tempos em que se passem suas tramas, em grande parte longe da Inglaterra e da época de Shakespeare, com personagens que, já na Grécia antiga, já no medievo de Verona ou, ainda, na Dinamarca, agem como ingleses da virada do século XVI para o XVII.

Assim, como se viu, Sonho... culmina na encenação de uma peça dentro da peça, neste caso a apresentação organizada pelos trabalhadores braçais de uma tragédia de cerca de dez palavras ("some ten words long" [5.1.66]) como homenagem à celebração das bodas de Teseu e Hipólita, que se postam, ao lado dos dois casais de enamorados na condição de espectadores críticos. Intitulada "A tedious brife scene of young Pyramus and his love Thisbe: very tragical myrth" ("Cena Curta e Chata de Tisbe e Píramo, Amantes: A Mais Trágica Alegria” [5.1.60]), a precária apresentação teatral dos trabalhadores mostra-se melodramática, risível e, ao mesmo tempo, uma paródia da estrutura trágica empregada mesmo por Shakespeare alhures, como em Romeu e Julieta.

Considere-se, à guisa de exemplo, como o ritmo trágico dos pentâmetros iâmbicos das cenas de maior gravidade em Sonho... (tais como nas falas de Teseu dirigidas a Hipólita e, de forma especular, nas altercações entre Oberon e Titânia) cede lugar a versos menores, prototípicos do falar dos seres feéricos na peça e associados aos elisabetanos a temas leves e risíveis: "O dainty duck, O dear! / Thy mantle good, / What, stained with blood? / Approach, ye furies fell / O fates, come, come, / Cut thread and thrum, / Quail, crush, conclude and quell” [“Oh, pombinha graciosa! / Teu manto, aqui, / Com sangue, assi'. / Ó Fúrias, vinde cá. / Fiapos e linha / Da vida minha / Cortai, ó Parcas, já”] (5.1. 293-303). Percebe-se pois aí a paródia à tragédia a efetivar-se assim pela estrutura, como pelos temas, inclusive 
de inspiração clássica, como nas referências às Fúrias, às Parcas e à linha da vida, além, naturalmente, da alusão às Metamorfoses de Ovídio por meio das personagens Píramo e Tisbe. Esta abordagem burlesca de Shakespeare em relação à tragédia - não apenas ao modelo trágico antigo, como também à tragédia elisabetana - e, ao mesmo tempo, em relação aos modelos míticos e épicos (conquanto metamorfoseado em si próprio seja a obra ovidiana), aproxima-se do que Sutton chama de travesty, apresentação caricata com toques de humor pastelão (slapstick) que há no drama satírico grego relativamente a tramas mitológicas. ${ }^{23}$

Este riso é motivado não apenas nas situações ridículas em que Eurípides põe Odisseu em o Ciclope, mas também por meio dos duplos sentidos que o complementam. Lembre-se, pois, desta ocorrência, em um dos fragmentos do drama satírico Dionusískos,

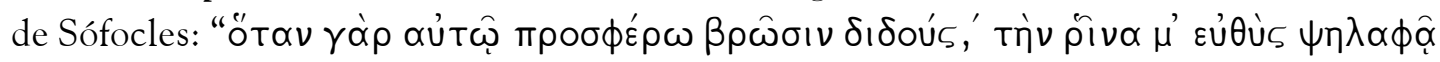

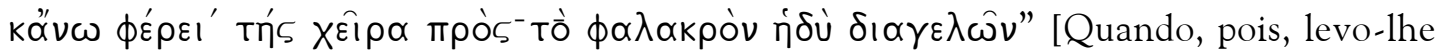
comida, a ele a oferecê-la, de imediato ele toca-me o nariz e, a rir docemente, leva a mão à minha parte careca]. Há aí um jogo de sentido (pun), conforme aponta W. Slenders, ${ }^{24}$

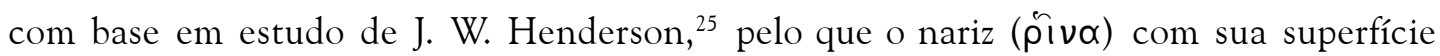
sem pêlos está pelo membro viril que, qual brinquedo, provoca o riso pueril. Um precedente cômico para tal duplo sentido encontra-se, ainda como aponta Slenders, nos versos 538 e 539 de Nuvens, nos quais Aristófanes descreve situação semelhante:

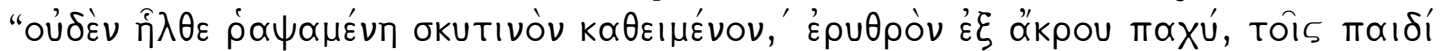
ols 'iv' ᄁ̣ $\gamma \varepsilon \dot{\varepsilon} \lambda \omega \varsigma$ ” [e ela vem sem trazer, preso a si, um penduricalho de couro, vermelho na ponta, grosso, para o riso dos meninos]. Tomadas em conjunto, são essas conotações de "careca" e "vermelho brilhante" que, recorda Slenders ${ }^{26}$ com base em R. Cantarella, ${ }^{27}$ remetem ainda ao drama satírico Diktyulkoí, em que Ésquilo retrata Perseu como um menino desejoso de brincar com a "careca escarlate" de Sileno, que, por seu turno, deseja

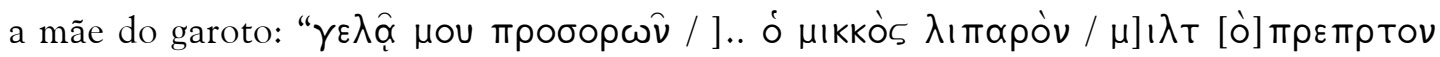
$\phi \alpha \lambda \alpha k \rho o ̀ v "$ [Ri-se o pequeno, avistada a minha brilhante careca escarlate].

Ainda na encenação dos trabalhadores braçais no último ato de Sonho... é a ambiguidade dos termos que, pretensiosamente trágicos, tornam-se risíveis que serve para a figuração do derrisório, como se observa, por exemplo, no emprego de stones, palavra que, além de significar "pedra”, é gíria elisabetana para testículos (recuperada na tradução pela ambiguidade do termo "bolas") - quando a pseudograndiosidade dos pentâmetros iâmbicos desaba de vez com Novelo, no papel de Píramo, a dizer ao muro que o separa de Tisbe: "O wicked wall, through whom I see no bliss, / Cursed be thy stones for thus deceiving me" ["Cruel muro, a alegria não tem vez. / Malditas as tuas bolas de reboco" (v. 190)]. Mais abertamente chulo, isto ocorre também quando Foles, que interpreta Tisbe, diz ao mesmo muro: "often kissed thy stones / thy stones with lime and hair..." ["Beijei teu reboco [...] / Tuas bolas de reboco embolado"] (5.1.200-201).

\footnotetext{
${ }^{23}$ SUTTON. The Satyr Play, p. 94.

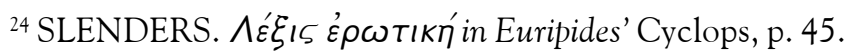

${ }^{25}$ HENDERSON. The Maculate Muse.

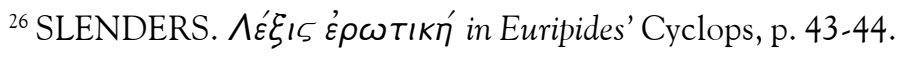

${ }^{27}$ CANTARELLA. I nuovi framenti eschilei di Ossirinco.
} 
Ainda que Shakespeare faça uso recorrente desses jogos de duplicidade em suas comédias e, mesmo, em partes específicas de riso na tragédia (como nas falas ludibriosas e dúplices que Hamlet dirige a Ofélia), o que determina sua aproximação com o drama satírico nesse uso é justamente a modulação cênica que a traz, em função burlesca relativamente à estrutura da tragédia, mais toques de humor de expressão física (por meio de gestos e outros recursos visuais, como danças espalhafatosas). ${ }^{28} \mathrm{O}$ emprego da linguagem, dos recursos e mesmo dos metros da tragédia, enfim, servem ao drama satírico, segundo Sutton, ${ }^{29}$ ao serem modificados pelos poetas com vistas às demandas deste gênero, exercido em relação àquele. No drama satírico estes efeitos, e outros que se coadunam, engendram uma ambiência trágica, conforme assinala Sutton, ${ }^{30}$ pelo que remetem à encenação da tragédia para, então, de modo deliberado, destruir-se pela técnica dramática este construto trágico e provocar, com isso, o riso.

Em função de paródia, há ocorrência análoga, em momento pontual, na peça dos trabalhadores, embora o trágico não se desenvolva muito claramente ali, tão risível é a tentativa de encená-lo. A peça dentro da peça serve, de outro modo, para encerrar com certo escárnio, mais do que com riso, as possibilidades trágicas que se aventaram no início da trama central relativamente a Lisandro e a Hérmia, pois o casal de jovens foge para os perigos do bosque a fim de se casar e permite circunstâncias que, em outras peças, Shakespeare facilmente reverteria para a morte trágica. ${ }^{31}$ Tem-se, pois, em Sonho... o espelhamento entre o drama satírico, pontuado na cena dos trabalhadores, e a reversão dos componentes trágicos da trama central, que se convertem no riso cômico que emoldura a peça e culmina na celebração do casamento, conforme costuma ocorrer nas comédias shakespearianas.

A comicidade reveste-se, por seu turno, de componentes satíricos em sua acepção latina. Exemplo disso ocorre antes da cena dos trabalhadores, quando se anunciam, ao lado dela, outras apresentações que poderiam ser ali realizadas, entre as quais a de título "the thrice-three muses mourning for the death / of learning, late deceased in beggary" [Três Vezes Três Musas e seu Lamento / Na Morte do Sábio que Era Mendigo] (5.1 56-57). Esta parece ser uma alusão a Robert Greene, um dos University Wits ${ }^{32}$ que criticou Shakespeare, então a iniciar sua carreira como ator e dramaturgo, e que, apesar de brilhante em seus escritos, morreria na miséria. Distante do drama satírico, em que

\footnotetext{
${ }^{28}$ Dança desta natureza, apontada por Sutton (The Satyr Play, p. 94) como elemento do drama satírico, está presente no encerramento de Sonho....

${ }^{29}$ SUTTON. The Satyr Play, p. 94.

${ }^{30}$ SUTTON. The Satyr Play, p. 95.

${ }^{31}$ No drama shakespeariano, convém lembrar, são tenuíssimos os limites estruturais e, mesmo, formais entre comédias e tragédias, de modo que, fosse em uma tragédia como Romeu e Julieta, a fuga dos jovens rumo ao bosque, assim como ocorre com Romeu a exilar-se em Pisa, provocariam conseqüências nefastas.

${ }^{32}$ Assim se denominam os dramaturgos elisabetanos com formação universitária, já em Cambridge, já em Oxford, quando não em ambas, como foi o caso de Greene, que se graduou na primeira instituição e se tornou Magister Artium (MA) na segunda. Também poeta e autor de pujantes textos em prosa, Greene faleceu em 1592, cerca de três anos antes da data provável de composição de Sonho..... Quando o novato Shakespeare despontava junto ao público, Greene o alcunhou de upstart crow, expressão denotativa de uma exuberância desengonçada, qual a do corvo, porém autoconfiante.
} 
não se costumava fazer críticas a personalidades coetâneas, e algo semelhante à comédia ática antiga, configura-se aí o exercício da sátira no sentido latino da crítica aos vícios feitas, por exemplo, por Ben Jonson com base em Juvenal. ${ }^{33}$

Esta assimilação conceitual que mescla elementos do drama satírico grego e da sátira latina permeia, pois, a estrutura de Sonho... e realiza-se no palco por meio da divisão da trama em dois planos de ação, o dos humanos e o dos seres feéricos, estes a interferir nas atitudes daqueles. São os seres feéricos, com efeito, que, olhados mais de perto, permitem perceber características pontuais de caracterização que os aproximam da figuração dos sátiros no drama satírico grego. Não se trata, naturalmente, de afirmar peremptoriamente que Shakespeare construiu tais personagens a partir dos modelos dos sátiros, mas, do contrário, de perceber como a presença das fadas em Sonho..., além de permitir a realização no palco de elementos do drama satírico, traz em si aspectos dos sátiros como aqueles que se veem em $\mathrm{O}$ conto de inverno.

Tal como os sátiros de Ésquilo, Sófocles e Eurípides, as fadas de Shakespeare não raro constituem um coro, em que Puck, corifeu a seu modo, comenta a ação para si em tom de deboche ou de escárnio, de modo a ser ouvido pela plateia, quando não se dirige diretamente aos espectadores. Atrelam-se as fadas e os elfos ${ }^{34}$ à ambiência do bosque, livres da influência das leis da civilização, pois uma região tal como as florestas era o locus que a convenção teatral elisabetana reservava ao instinto, à selvageria e, também, à magia como elementos irrefreáveis.

$\mathrm{Na}$ literatura dramática pintavam-se os bosques a circundar o campo, ambiente associado aos camponeses e a produção agrícola, entorno da cidade, que representava, por seu turno, o local das relações de casamento e comércio de uma incipiente classe média a que pertenceriam os jovens de Sonho..., em cujo centro encontrava-se a corte, palco das grandes tragédias, como Hamlet, Rei Lear e Macbeth. Eis, portanto, mais uma das características análogas ao drama satírico, uma vez que "(...) Soweit wir sehen können, spielen fast alle Satyrspiele nicht vor einem Palast (wie die meisten Tragödien) oder in der Stadt (wie fast alle Komödien), sondern dort, wo die Satyrn zu Hause sind, d.h. in der freien Natur: in Bergwäldern und Einöden, vor Höhlen oder am Meeresstrand." [Ao menos pelo que podemos ver, quase todos os drama satíricos são encenados não ante um palácio (como a maioria das tragédias) nem em uma cidade (como quase todas as comédias), mas ali onde os sátiros estão em casa, isto é, na natureza livre: em bosques monteses e no ermo, ante cavernas ou na orla do mar]. ${ }^{35}$

\footnotetext{
${ }^{33}$ SUTTON. The Satyr Play, p. 95.

${ }^{34}$ Mesmo antes do nascimento de Shakespeare, os termos "elfo" e "fada" já eram utilizados indistintamente em algumas de suas ocorrências, pois esses seres não pertencem a um sexo apenas, pelo que se pode falar de uma fada do sexo masculino, que não é um elfo. Consoante os romances medievais, Shakespeare localiza o Reino das Fadas em meio a elementos vegetais e minerais. A esse respeito, em sua compilação de documentos relativos às concepções de fada dentre os elisabetanos, Frank Sidgwick (The Sources and Analogues of A Midsummer-Night's Dream) assevera que a forma original de "fada" é fay, cujo plural, fairy, designava a coletividade das fadas ou, por metonímia, a terra das fadas, além de significar "encantamento", tendo origem no nominativo neutro fata (plural de fatum, "fado", "destino"), que foi confundido com um substantivo feminino singular.
}

35 SEIDENSTICKER. Über das Vergnügen na tragischen Gegenständen, p. 376. 
Porque essencialmente associados por essa ambiência dos bosques, as fadas e os elfos são partícipes de um caráter elemental por meio de certa subjetividade configurada pela personificação do instinto (que se faz incidir sobre o desejo das personagens humanas e assim permite as reviravoltas da trama) em formas naturais e viventes, como flores e animais. Este traço natural revela-se nos próprios nomes das fadas, a saber, Peaseblossom (Semente-de-Ervilha), Cobweb (Teia-de-Aranha), Mustardseed (Semente-de-Mostarda), Moth (Cisco), os quais, consoante comparação de Tereza Virgínia R. Barbosa, remetem a alguns daqueles nos sátiros nos dramas satíricos helênicos: Scóps (Mocho), Krókias (Açafrão), Hedymelés (Canto-Doce), Hedýoinos (Vinho-Doce), Oinopíon (Rúbio) e Trechis (Broto). ${ }^{36}$

Conquanto germânicos em seus protótipos e anglo-saxônicos (isto é, da cultura antiga e medieval da Inglaterra) em sua apropriação, as fadas de Shakespeare trazem em sua própria concepção influências dos antigos gregos e romanos. A esse respeito, é basilar a asserção de Thomas Nashe, douto contemporâneo de Shakespeare que afirma que os robins-bons-camaradas (Robbin-good-fellowes, figuras do folclore inglês cujos atributos em parte, bem como o nome, Shakespeare mescla a Puck), elfos (Elfes), fadas (Fairies), duendes (Hobgoblins) de "nossa época tardia" ("our latter age”) relacionam-se aos faunos, sátiros, dríades e hamadríades dos dias anteriores ("former daies") do "fantástico mundo da Grécia" ("fantasticall world of Greece"). ${ }^{37}$ Outro contemporâneo de Shakespeare, Edmund Spenser explica a origem dos elfos associando-os, em Faerie Queene (2.10.70), a Prometeu: “...Prometheus did create / A man of many parts from beasts deryved; That man so made he called Elfe... [“... Prometeu de fato criou um homem com muitas partes de bestas oriundas; A este homem, assim feito, elfo ele chamou...”].

As características em comum ora analisadas entre o drama satírico grego e Sonho..., é lícito asseverar, constituem menos um simples paralelo do que indícios ou vestígios da proximidade entre a peça shakespeariana e o gênero antigo. Tal asserção justifica-se pela presença de elementos do drama satírico em peças shakespearianas, sobretudo nas tragédias, mas também em $\mathrm{O}$ conto de inverno, conforme reconhecido pela crítica. A determinação destes elementos centra-se em princípio na adaptação ou reapropriação de uma atitude teatral que se vale da tragédia e do épico como matéria do riso, oriundo particularmente da paródia, o que se converteu, pela recepção do drama satírico no início da modernidade, no burlesco. A bem da verdade, uma espécie de burlesco expresso no satirizar-se veiculado pela própria indistinção, corrente à época, entre o satírico grego e o satírico latino. Vê-se, ademais, que na própria configuração dos seres feéricos, fundamentais para o exercício satírico em Sonho..., há elementos greco-romanos assimilados desde o Medievo inglês.

Por fim, conforme demonstrada pelas características cênicas intrínsecas ao texto da peça ora estudada, como no uso de linguagem coloquial e ambígua, a modulação destes elementos no palco elisabetano desvela a construção de uma espécie de riso que, para além daquele de natureza cômica justificado pelo gênero desta peça, demonstrase outrossim próxima ao que se concebia como satírico em sua relação ao drama satírico.

\footnotetext{
${ }^{36}$ BARBOSA. Os sátiros em Diktyulkoi, Ichneutas e Ciclope, p. 12.

${ }^{37}$ NASHE. The Terrors of the Night, p. 345.
} 


\section{A B S TR A C T}

By proceeding with a brief review of studies that have related Greek satyr drama to Shakespeare's tragedies, as well as to The Winter's Tale, I aim to demonstrate that those findings also prove accurate as for comedy, at least as it is carried out in A Midsummer Night's Dream. For doing so, I examine parody and burlesque in the play as being indicative of a literary mode set within and conveyed through this Shakespearean comedy with roots that can be traced back to Greek satyr drama no less than to early modern (prior to Casaubon) theoreticians' somewhat mingled view of satiric both as the Greek genre and the non-related Latin satire.

\section{KEYWORDS}

Shakespeare, Satyr-Play, A Midsummer Night's Dream

\section{REFERÊNCIAS}

AMBROSE, Z. P. Family Loyalty and Bretrayal in Euripedes' Cyclops and Alcestis: A Recurrent Theme in Satyr Play. In: HARRISON, G. W. M. (Ed.). Satyr Drama. Tragedy at Play. Swansea: The Classical Press of Wales, 2005. p. 21-38. 307 p.

BALDWIN, T. W. William Shakespeare's Small Latine and Lesse Greeke. Urbana: University of Illlinois Press, 1944. 2 v. 1.488 p.

BARBOSA, Tereza Virgínia R. Os sátiros em Diktyulkoi, Ichneutas e Ciclope. Manuscrito de conferência proferida no 3o Simpósio de Estudos Clássicas da USP, 30 out. 2008.

BARKAN, Leonard. What did Shakespeare read? In: GRAZIA, M. de; WELLS, S. The Cambridge Companion to Shakespeare. Cambridge: Cambridge University Press, 2001. p.31-46. 348 p.

CANTARELLA, R. I nuovi frammenti Eschilei di Ossirinco. Napole: Libr. Scientifica, 1948. $188 \mathrm{p}$.

CASAUBON, Isaac. De satyrica Graecorum poesi et Romanorum satira libri duo. Ed. T. Hala, 1784. 508 p.

DEMETRIUS. On Style. Greek/English. Ed./Trans. W. Rhys Roberts. Cambridge: Cambridge University Press, 1902. 341 p.

DEWAR-WATSON, Sarah. Shakespeare's Dramatic Odysseys: Homer as a Tragicomic Model in Pericles and The Tempest. Classical and Modern Literature, 25/1, p. 23-40, 2005.

DIHLE, Albrecht. A History of Greek Literature from Homer to the Hellenistic Period. London: Routledge, 1994. 344 p.

EURIPIDES. Cyclops. Bilingual Edition Greek/English. Trans. David Kovacs. Massachusetts: Harvard University Press, 1994. 432 p.

EWANS, Michael. Patterns of Tragedy in Sophokles and Shakespeare. In: SILK, M. S. (Ed.). Tragedy and the Tragic. Greek Theatre and Beyond. Oxford: Clarendon, 1998. p. $438-457.576$ p. 
FRYE, Northrop. Anatomy of Criticism: Four essays. Princeton: Princeton University Press, 1957.383 p.

GOODWIN, Thomas. Romanae Historiae Anthologia Recognita et Aucta. An English Exposition of the Roman Antiquities: Wherein many Roman and English Offices are parallel'd, and divers obscure Phrases explain'd. For the use of Abingdon School. London, 1680. 277 p. HENDERSON, J. W. The Maculate Muse. Obscene Language in Attic Comedy. Oxford: Oxford University Press, 1991. 288 p.

HUNTER, G. K. Dramatic Identities and Cultural Tradition: Studies in Shakespeare and his Contemporaries. Liverpool: Liverpool University Press, 1978. 376 p.

JONES, Emry. The Origins of Shakespeare. Oxford: Oxford University Press, 1977. 298 p. KARLSSON, R. Svensk-franska förhandlingar. Bland sprätthökar och franska flugor I svenskt 1700-tal. Linköping Studies in Arts and Science nr. 398. Linköping (Sweden): Linköpings Universitet, 2007. 250 p.

KAUFMANN, Walter. Tragedy and Philosophy. 2. ed. Princeton: Princeton University Press, 1979. 480 p.

KITTO, H. D. F. Form and Meaning in Drama: A Study of Six Greek Plays and Hamlet. London: Methuen, 1956. 351 p.

MAcINTOSH, Fione. The Big Speech and the Lament in Ancient Greek and Modern Irish Tragic Drama. In: SILK, M. S. (Ed.). Tragedy and the Tragic. Greek Theatre and Beyond. Oxford: Clarendon, 1998. p. 414-425. 576 p.

MIOLA, Robert S. Shakespeare's reading. Oxford: Oxford University Press, 2000. 200 p. MITCHELL-BOYASK, Robin. On the Uses and Abuses of Girard and Shakespearean Criticism. In: SILK, M. S. (Ed.). Tragedy and the Tragic. Greek Theatre and Beyond. Oxford: Clarendon, 1998. p. 426-437. 576 p.

NASHE, Thomas. The Terrors of the Night. Or a Discourse of Apparitions. In: McKERROW, Ronald (Ed.). The Works of Thomas Nashe. London: A. H. Bullen, 1904. 6 v. v. 1. 468 p. ORGEL, Stephen. The Authentic Shakespeare, and Other Problems of the Early Modern Stage. New York: Routledge, 2002. 296 p.

PUTTENHAM. The Arte of English Poesie. 2. ed. Cambridge: Cambridge University Press, 1970. 459 p.

RAMAlHO, Erick. Estudo introdutório. In: JOHN, Milton. Poemata. Poemas em latim e em grego. Organização, tradução, estudo tradutório e comentário por Erick Ramalho. Belo Horizonte: Tessitura, 2008. 456 p.

SCHLEINER, Louise. Latinized Greek Drama in Shakespeare's Writing of Hamlet. Shakespeare Quarterly, Folger Shakespeare Library, v. 41, n. 1, p. 29-48, Spring 1990.

SEIDENSTICKER, Bernd. Über das Vergnügen an tragischen Gegenständen: Studien zum antiken Drama. Jens Holzhausen (hg.). Berlin: De Gruyter, 2005. 454 p.

SHAKESPEARE, William. The Complete Works. Oxford: Oxford University Press, 1986. $1.456 \mathrm{p}$.

SHAKESPEARE, William. Sonho de uma noite de verão. Tradução, introdução e notas de Erick Ramalho. Belo Horizonte: Tessitura, 2006. 192 p. 
SIDGWICK, Frank. The Sources and Analogues of A Midsummer-Night's Dream. London: Chatto \& Windus, 1908. 196 p.

SILK, M. S. The Greek Tragedians and Shakespeare. In: SILK, M.S. (Ed.). Tragedy and the Tragic. Greek Theatre and Beyond. Oxford: Clarendon, 1998. p. 458-496. 576 p.

SLENDERS, Willeon. Het Griekse satyrspel. In: HERMENEVS. LXXV/I, p. 23-29.

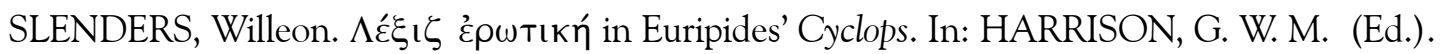
Satyr Drama. Tragedy at Play. Swansea: The Classical Press of Wales, 2005. p.39-52. 300 p. SPENSER, Edmund. The Faerie Queene. Ed. Smith, J. C. Oxford: Clarendon, 1909. 3 v. v. $2.519 \mathrm{p}$.

STYAN, J. L. Shakespeare's Stagecraft. Cambridge: Cambridge University Press, 1967. $256 \mathrm{p}$.

SUTTON, Dana F. The Greek Satyr Play. Meisenheim am Glan: Hain, 1980. 215 p.

SUTTON, Dana F. The Satyr Play. In: EASTERling, P. E.; KNOX, B. M. W. (Ed.). The Cambridge History of Classical Literature. Cambridge: Cambridge University Press, 1989. v. 1, part 2. p. 94-102. 232 p.

SYDNEY, L. E.; WILLIAMSON, J. C. Antony and Cleopatra. Komos, a Quarterly Journal of Drama and the Arts of the Theatre. Monash University (Australia), v. 1, p. 128-139, 1968. 